\title{
Economic Evaluation of Ferric Carboxymaltose for the Management of Hemodialysis Patients with Iron Deficiency Anemia in Italy
}

\author{
Carla Rognoni (D) - Vittorio Ortalda - Caterina Biasi - Giovanni Gambaro
}

Received: August 7, 2019 / Published online: September 5, 2019

(c) The Author(s) 2019

\begin{abstract}
Introduction: Patients with chronic kidney disease on hemodialysis (HD) are at high risk of developing both iron deficiency and iron deficiency anemia (IDA). The administration of intravenous iron therefore represents the standard of care for the management of anemia in this patient setting.

Methods: A retrospective cohort of $38 \mathrm{HD}$ patients in Italy was analyzed to assess the clinical and economic implications of switching from intravenous ferric gluconate (FG) to ferric carboxymaltose (FCM) on achievement of adequate hemoglobin $(\mathrm{Hb})$ values and iron balance. The total observational period for each patient was 12 months, 6 months before and 6 months
\end{abstract}

Enhanced Digital Features To view enhanced digital features for this article go to: https://doi.org/10.6084/ m9.figshare.9752492.

Electronic Supplementary Material The online version of this article (https://doi.org/10.1007/s12325$019-01089-z)$ contains supplementary material, which is available to authorized users.

C. Rognoni ( $\square)$

Centre for Research on Health and Social Care

Management (CERGAS), SDA Bocconi School of

Management, Bocconi University, Milan, Italy

e-mail: carla.rognoni@unibocconi.it

V. Ortalda · C. Biasi · G. Gambaro

Nephrology and Dialysis Division, AOUI Verona, Verona, Italy after switching to iron FCM. The pharmacoeconomic analysis considered the hospital perspective and the consumption of iron, blood transfusions and erythropoiesis-stimulating agents (ESAs), including healthcare personnel time.

Results: Switching from FG to FCM in dialysis adult patients with IDA allows a cost reduction per patient/month in the range $€ 14-46$, considering the use of biosimilar ESA or originator ESA, respectively. The percentage of patients with $\mathrm{Hb}$ target values increased from $63 \%$ to $82 \%$, considering the entire observation period. In addition, other clinical parameters (ferritin, transferrin saturation, erythropoietin resistance index) improved after switching from FG to FCM.

Conclusion: FCM in HD patients was shown to provide a favorable efficacy profile over FG, with a lower cost per patient, mainly driven by a consistent reduction of ESA consumption.

Funding: Vifor Pharma Italia Srl.

Keywords: Budget; Cost-analysis; Healthcare; Hemodialysis; Ferric carboxymaltose; Nephrology

\section{INTRODUCTION}

Patients with chronic kidney disease (CKD) on hemodialysis (HD) are at high risk of developing both iron deficiency and iron deficiency anemia 
(IDA), with prevalence rates reaching as high as $80 \%$. This is mainly attributed to reduced iron absorption, chronic inflammatory processes and increased blood loss $[1,2]$.

The availability of adequate iron doses for erythropoiesis is a key factor in allowing a good response to erythropoiesis stimulating agents (ESAs). In cases of absolute or functional iron deficiency, it is necessary to use higher doses of ESAs to obtain a significant erythropoietic response. This is frequent in cases of resistance or hyporesponsiveness $[1,2]$.

In dialysis patients, the administration of oral iron is frequently ineffective and is often associated with gastrointestinal side effects. Renal failure is associated with upregulation of the iron regulatory peptide hepcidin, which binds to the iron exporter protein ferroportin and thereby reduces iron export from the enterocytes into the plasma, thus limiting dietary uptake. Intravenously administered iron, which bypasses the gastrointestinal tract, leads to faster iron incorporation into bone marrow red blood cells and hemoglobin [3]. The administration of intravenous (IV) iron therefore represents the standard of care for the management of anemia in this patient setting, with a tendency to both increase iron doses and reduce the use of erythropoietin $[4,5]$. In this way, both costs and potential risks are optimized, particularly in terms of reduction of major thromboembolic events and related mortality, as shown in several trials [6, 7]. If from one side IV iron overcomes the ineffectiveness of oral formulations, on the other hand, even acute anaphylactoid reactions during iron infusions may happen, although lifethreatening in rare cases [8].

Nowadays, data on the use of various IV iron preparations in dialysis are still limited, leading to heterogeneity in administration methods, doses and duration of treatment, with a different impact on the outcomes observed [5].

In Italy, three IV iron formulations are currently available: ferric gluconate (FG, Ferlixit ${ }^{\circledR}$ Sanofi-Aventis), iron sucrose (IS, Venofer ${ }^{\circledR}-\mathrm{Vi}$ for Pharma) and ferric carboxymaltose (FCM, Ferinject ${ }^{\circledR}$-Vifor Pharma), all formulations having different characteristics. FCM is a newgeneration non-dextran-like IV iron, characterized by a high molecular weight and chemical-structural characteristics (external shell of carboxymaltose), allowing the release of iron in a controlled manner, thus permitting high dose infusions in a single administration (up to $1000 \mathrm{mg}$ during a $15 \mathrm{~min}$ infusion) [9].

Although the efficacy of the three formulations for the treatment of anemia in patients with CKD has been studied individually by comparing individual preparations with oral supplementation [10-12], there is still a lack of head-to-head studies among the various IV formulations, particularly in the dialysis population.

Some studies have shown that FCM is well tolerated and effective in correcting hemoglobin $(\mathrm{Hb})$ levels in patients with CKD undergoing dialysis $[13,14]$.

A recent Dutch study [15] showed that the switch from IS to FCM in HD patients was associated with a significant improvement in iron status and $\mathrm{Hb}$ values, unrelated to IV iron dose. Furthermore, weekly doses of ESA decreased after switching to FCM.

The PIVOTAL trial [16], the largest prospective randomized study, recruiting 2171 HD patients, has recently provided important safety results. This study has demonstrated, for the first time, that the use of a liberal, proactive higher dose IS regimen [aimed at targeting higher ferritin and transferrin saturation (TSAT) values] was superior to the use of a low-dose, reactive IS regimen and was associated with a lower risk of major cardiovascular events (acute myocardial infarction, stroke, hospitalization for heart failure or mortality) and did not increase the risk of all-cause mortality. Moreover, a proactive IV iron treatment regimen also allowed the use of lower ESA doses and required fewer transfusions in HD patients [17].

Here we present results of a retrospective real-world study performed in a HD patient cohort aimed at providing further information on the clinical and economic implications that can support hospital decision makers in their choice of treatment of iron deficiency anemia. A comprehensive approach was performed by evaluating the effect of switching from FG to FCM on achievement of adequate $\mathrm{Hb}$ values 
and iron balance from a clinical and pharmacoeconomic point of view.

\section{METHODS}

\section{Patients}

FCM became available in our Dialysis Unit (Ospedale Maggiore, Division of Nephrology and Dialysis, AOUI Verona, Italy) from winter 2015. Thereafter, HD patients with iron deficiency, despite IV iron supplementation, were gradually switched from FG to FCM. In particular, the criteria for the switch were: lack of efficacy in reaching $\mathrm{Hb}$ target values $(\mathrm{Hb}<10.5 \mathrm{~g} / \mathrm{dl})$, inadequate iron status (ferritin $<200 \mu \mathrm{g} / \mathrm{l}$ or TSAT $<20 \%$ ) or evidence of a progressive increase of the Erythropoietin Resistance Index [ERI = erythropoietin (international units/week per $\mathrm{kg}) / \mathrm{Hb}(\mathrm{g} / \mathrm{dl})]$ with consequently increasing ESA costs. The experience gained with these patients was investigated in this study.

The study was approved by the ethics committee of AOUI Verona (study 2047CESC, reference no. ITSP2018) and conformed to the Helsinki Declaration of 1964, as revised in 2013, concerning human and animal rights. Data were retrospectively retrieved from the cohort of adult HD patients with IDA who used FG for at least 6 months and then switched to FCM for a further 6 months in the period from January 1, 2016, to November 30, 2018. On average, the patients were on dialysis for 14.3 years and have been treated with FG for 2.8 years.

\section{Study Design}

The total observational period for each patient was 12 months: 6 months before (month -6 ) and 6 months after switching from FG to FCM (month 6).

The main aim of this study was to perform a cost minimization analysis to estimate the economic impact of the treatment with FCM in the investigated population. This strategy has been compared with the "standard of care" in our Dialysis Unit, i.e., FG. Cost-minimization analysis is mostly applied in the health sector and is a method used to measure and compare the costs of different medical interventions considering that they provide the same effectiveness (no differences in terms of life expectancies) [18]. The analysis considered the hospital perspective and the consumption of iron, blood transfusions and ESAs, including healthcare personnel time.

Secondary objectives included identifying the percentage of patients reaching $\mathrm{Hb}$ levels $\geq 10.5 \mathrm{~g} / \mathrm{dl}$ after switching to FCM, evaluation of ERI and evaluation of the variation in ferritin and TSAT levels in the two study periods.

Data collection was retrospective. The following data were collected and/or calculated in the two different periods: (1) consumption of intravenous iron (FG, FCM): number of infusions, frequency of administration, cumulative dose; (2) consumption of erythropoietin: type, frequency of administration, dosage, ERI; (3) consumption of blood transfusions for anemia correction: blood units; (4) monthly $\mathrm{Hb}$ and TSAT values.

Clinical parameters and consumption of iron, erythropoietin and blood transfusions were measured monthly as for routine practice.

\section{Treatment Protocol and Healthcare Resource Consumption}

The iron treatment protocol applied in the hemodialysis ward considered an induction phase for FG of 15 infusions of $62.5 \mathrm{mg}$ each, while for FCM 10 infusions of $100 \mathrm{mg}$ each were applied (for FCM a single maximum daily dose of $200 \mathrm{mg}$ iron should not be exceeded in HD patients) (1000 mg cumulative elemental iron in both cases). The maintenance dosing schedules for FCM and FG consisted of 100-200 mg and $125 \mathrm{mg}$ of elemental iron, respectively, given every 2-4 weeks, with corrections based on $\mathrm{Hb}$ values and patients' weights as reported by the summary of product characteristics of the two iron formulations.

The aim of the iron therapy was to let patients reach and maintain target values for $\mathrm{Hb}$ $(\geq 10.5 \mathrm{~g} / \mathrm{dl}), \quad$ TSAT $(\geq 20 \%)$ and ferritin 
( $\geq 200 \mu \mathrm{g} / \mathrm{l}$ ). ESA consumption was modulated taking into account the different available formulations according to reached $\mathrm{Hb}$ values.

Data on treatment costs (e.g., consumables) and personnel time dedicated to the different activities were collected through direct elicitation from clinicians in charge of patients.

Clinicians reported that about $20 \%$ of IV iron infusions are performed directly through syringe, the rest being infused via pump syringe. The estimated nursing time was 10 and $5 \mathrm{~min}$, respectively.

We considered only blood transfusions that were undertaken for the management of chronic/subacute anemia. Transfusions performed for acute anemia (i.e., hematoma, gastrointestinal bleedings, etc.) or elective surgery were excluded from the analysis. The dedicated time of the physician and the nurse for the blood transfusion was estimated to be $5 \mathrm{~min}$ each.

ESA infusions were performed using pre-filled syringes. Therefore, only the cost of erythropoietin was considered in the analysis, with no cost for personnel time. Three ESAs were used according to local clinical practice: two originators (epoetin alpha, Eprex ${ }^{\circledR}$ and epoetin beta, Neorecormon ${ }^{\circledR}$ ) and one biosimilar (epoetin alpha, Binocrit ${ }^{\circledR}$ ). Almost all patients used the same ESA for the entire observation period; two patients in the post-switch period changed from the originator (Eprex) to the biosimilar and three patients changed from an originator to the other originator. In the former case, the unit cost of the originator was also applied in the post-switch period to avoid any overestimation of saving due to the lower cost of biosimilars; in the latter case, the unit cost of Eprex was used for consistency for the entire observation period since the difference in cost of the two originators is negligible.

In the base case scenario, for each healthcare resource (e.g., iron, blood transfusions, etc.), the cumulative consumption was calculated. The monetary quantification of the different healthcare resources was performed based on hospital prices provided by the Hospital Administrative office. It can be highlighted that FCM is more expensive than FG therapy at equivalent doses (e.g., the cost for $1000 \mathrm{mg}$ is
$77.50 €$ and $10.08 €$ for FCM and FG, respectively).

Healthcare resources and related costs are shown in Table 1.

As the current trend in Italy is to promote the use of biosimilars, which cost less than originators, a scenario analysis considered the price of ESA biosimilar for all patients for both periods.

In addition to the total cost per period (preswitch and post-switch) and per patient/month, the cost per patient at target values of $\mathrm{Hb}$ was calculated for FG and FCM. This was obtained by dividing the total cost for the period by the number of patients reaching $\mathrm{Hb}$ target values (i.e., $\geq 10.5 \mathrm{~g} / \mathrm{dl}$ ).

\section{Statistical Analyses}

Numerical variables were summarized using means and standard deviations. Categorical variables were summarized using numbers and percentages. Comparison of differences between groups was performed using the $t$ test or Wilcoxon test (continuous variables). The evaluation of statistical differences among time trends in the two periods considered was performed using a paired $T$ test for the comparison of the slopes of two regression lines (one per period). A $p$ value $<0.05$ was considered statistically significant. All statistical analyses were performed using STATA 14 (Statacorp LP Inc., College Station, TX, USA).

\section{RESULTS}

\section{Patient Characteristics and Treatment}

A total of 38 patients (53\% males), with mean age of $67 \pm 15$ years (range 39-91), were considered in this study.

In the pre-switch period, 1277 FG infusions of $62.5 \mathrm{mg} /$ each were performed, with a mean cumulative dose per patient of $2.1 \pm 0.49 \mathrm{~g}$ (range 1.1-3.5); in the post-switch period, the number of FCM infusions (100 $\mathrm{mg}$ each) was 748 , with a mean cumulative dose per patient of $2.0 \pm 0.66 \mathrm{~g}$ (range 0.9-3.7). The cumulative 
Table 1 Healthcare resources and costs

\begin{tabular}{lll}
\hline Healthcare resources & Unit cost & Reference \\
\hline FG $62.5 \mathrm{mg}$ & $€ 0.63$ & Hospital administrative office \\
FCM $100 \mathrm{mg}$ & $€ 7.75$ & Hospital administrative office \\
Blood transfusion unit & $€ 181.00$ & Hospital administrative office \\
Consumables for IV iron infusion (procedure with syringe) & $€ 0.73$ & Hospital administrative office \\
Consumables for IV iron infusion (procedure with syringe pump) & $€ 0.23$ & Hospital administrative office \\
Erythropoietin Eprex (1 IU) & $€ 0.0029$ & Hospital administrative office \\
Erythropoietin Neorecormons (1 IU) & $€ 0.0027$ & Hospital administrative office \\
Erythropoietin Binocrit $(1 \mathrm{IU})$ & $€ 0.0012$ & Hospital administrative office \\
Personnel time-nurse $(1 \mathrm{~h})$ & $€ 19.00$ & https://www.contoannuale.mef.gov.it \\
Personnel time-physician $(1 \mathrm{~h})$ & $€ 36.00$ & https://www.contoannuale.mef.gov.it \\
\hline
\end{tabular}

$F C M$ ferric carboxymaltose, $F G$ ferric gluconate, $I U$ international unit, $I V$ intravenous

doses in the 6-month periods were not statistically different $(p=0.36)$. The total number of blood transfusions reduced from 12 to 5 in the pre-switch and post-switch period, respectively. The total ESA consumption was 14,720,000 international units in the iron pre-switch period and decreased to $10,020,000$ international units in the post-switch period, equating to a reduction of $32 \%$.

\section{Healthcare Resource Consumption and Cost Analysis}

The total cost for 6 months of treatment was estimated at $€ 42,066$ ( $€ 184$ per patient/month) in the pre-switch period and $€ 31,569$ ( $€ 138$ per patient/month) in the post-switch period, with a cost saving of $€ 10,497$ ( $€ 46$ per patient/month; savings of 25\%), after changing from FG to FCM (Table 2). When use of biosimilar ESA in both the pre- and post-iron switch was considered, the cost saving was estimated at $€ 3126$ (€14 per patient/month; 13\%).

When the cost of healthcare personnel activities was excluded, the total costs were estimated to be $€ 39,595$ and $€ 30,125$ for the preswitch and post-switch periods, respectively, leading to savings of $€ 9460$ (24\%). When we considered the scenario of use of biosimilar ESA, savings of $€ 2089$ (10\%) were estimated.

$\mathrm{Hb}$ values decreased from $10.7 \pm 0.91 \mathrm{~g} / \mathrm{dl}$ to $9.9 \pm 0.99 \mathrm{~g} / \mathrm{dl}$ from month -6 to month 0 . After switching to FCM, Hb values moved from $10.98 \pm 0.80$ to $11.12 \pm 0.95 \mathrm{~g} / \mathrm{dl}$ (from month 1 to month 6) (Supplementary Fig. 1) $(p=0.0047)$. The percent of patients with optimal $\mathrm{Hb}$ levels $(\mathrm{Hb} \geq 10.5 \mathrm{~g} / \mathrm{dl})$ was $63 \%$ at time -6 but decreased to $29 \%$ at the time of switching (month $=0$ ). During FCM treatment, the percentage of patients with optimal $\mathrm{Hb}$ levels ranged from $66 \%$ to $82 \%$ (Fig. 1).

ERI (Fig. 2) showed a decreasing trend, starting from values in the range $20.9 \pm 16.1$ to $28.9 \pm 22.1$ in the pre-switch period toward values in the range $21.8 \pm 15.4$ to $12.6 \pm 10.9$ in the post-switch period $(p=0.002)$.

In the base case scenario, the mean cost for drugs (ESA and iron) per patient in the two periods was compared with monthly mean ERI values per patient (Fig. 3). In the pre-switch period, ERI remained stable with a mean monthly cost per patient of $€ 185$ over the period. In contrast, after switching to FCM, a timedependent decrease in cost was observed with a lower mean monthly cost per patient of $€ 153$.

Furthermore, both ferritin and TSAT mean values were observed to increase after switching 
Table 2 Total costs for pre- (FG) and post-switch (FCM) periods

\begin{tabular}{|c|c|c|c|c|}
\hline \multirow[t]{2}{*}{ Cost item } & \multicolumn{2}{|c|}{ Base case scenario } & \multicolumn{2}{|c|}{ Scenario with biosimilar ESA } \\
\hline & $\overline{\text { FG }}$ & FCM & $\overline{\text { FG }}$ & FCM \\
\hline Transfusions & $€ 2227$ & $€ 928$ & $€ 2227$ & $€ 928$ \\
\hline Iron + administration costs & $€ 3652$ & $€ 7465$ & $€ 3652$ & $€ 7465$ \\
\hline ESA & $€ 36,187$ & $€ 23,176$ & $€ 17,664$ & $€ 12,024$ \\
\hline Total cost & $€ 42,066$ & $€ 31,569$ & $€ 23,543$ & $€ 20,417$ \\
\hline
\end{tabular}

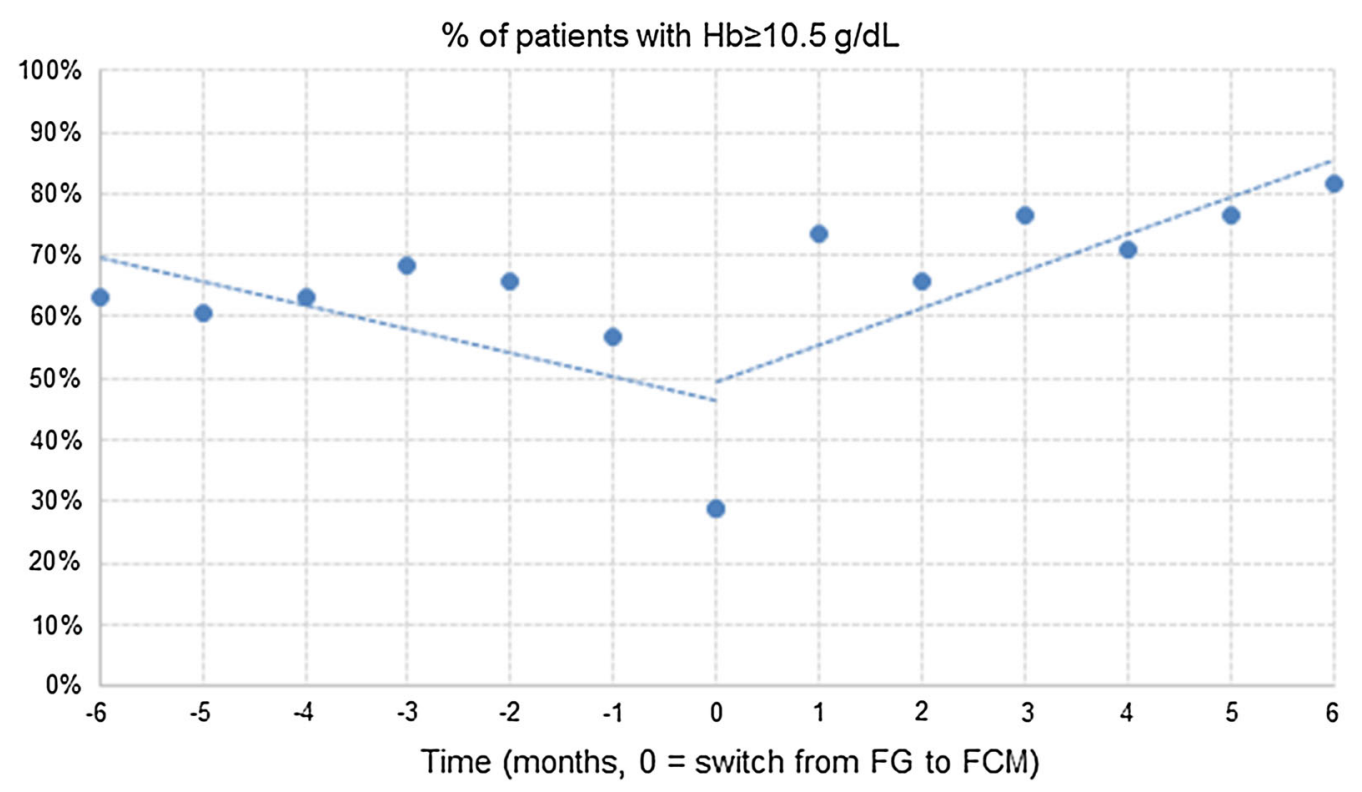

Fig. 1 Percentage of patients achieving target $\mathrm{Hb}$ values $(p=0.023$ for differences in trends over the two periods)

to FCM, as reported in Supplementary Figs. 2 and 3. Ferritin values moved from $66 \mu \mathrm{g} / \mathrm{l}$ at month 0 to $201 \mu \mathrm{g} / \mathrm{l}$ at month 6 , while TSAT values moved from $15.9 \%$ at month 0 to $22.1 \%$ at month 6. Mean ferritin values showed an increase of $+162 \%$ (mean value in FCM period $210.5 \mu \mathrm{g} / \mathrm{l})$ compared with the pre-switch period (mean value during FG period $80.3 \mu \mathrm{g} / \mathrm{l}$ ) $(p=0.0001)$, while TSAT increased by $+32 \%$ (mean value during FCM period $22.6 \%$, mean value during FG period $17.1 \%$ ) over the same period $(p=0.0001)$.

Transferrin values, indicating the iron-binding capacity, moved from a mean monthly value per patient of $2.06 \mathrm{~g} / \mathrm{l}$ during the FG $\mathrm{g} / \mathrm{l}$ period to 1.82 during the FCM period, showing an increased ability to satisfy the iron needs (transferrin is a protein synthesized in the liver, and in case of shortage of iron reserves the liver responds by increasing its production).

The percentage of patients showing TSAT values $>20 \%$ moved from $0 \%$ at month -6 to $60 \%$ (month 6) after the use of FCM (Supplementary Fig. 4) $(p=0.0032)$.

Figure 4 shows the IV iron administration schedule (monthly mean iron doses per patient) in the two considered periods in addition to $\mathrm{Hb}$ values (monthly mean $\mathrm{Hb}$ values per patient).

The cost per patient at achieving target values for $\mathrm{Hb}$ was $€ 1758$ in the pre-switch period and $€ 1120$ in the post-switch period, with a saving of $36 \%$. In the scenario that assumes the 


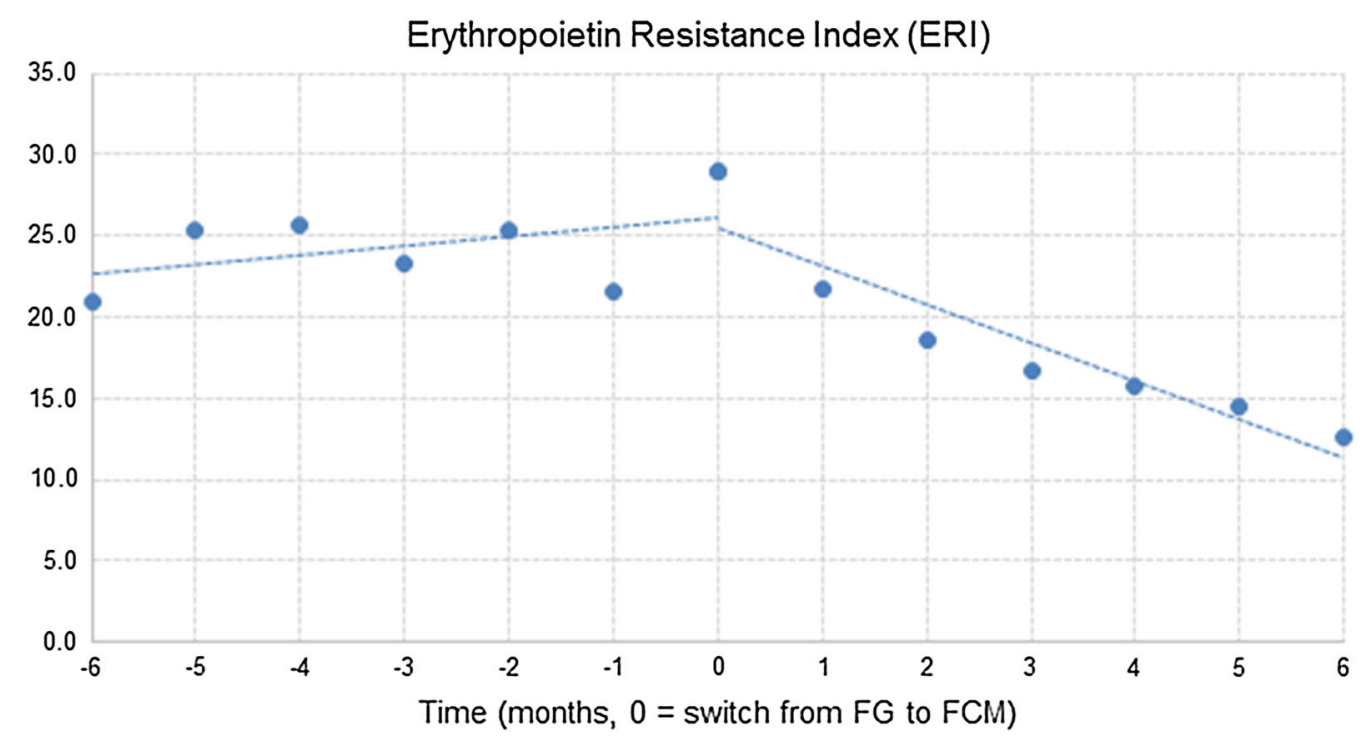

Fig. 2 Trend in Erythropoietin Resistance Index mean values over the two periods

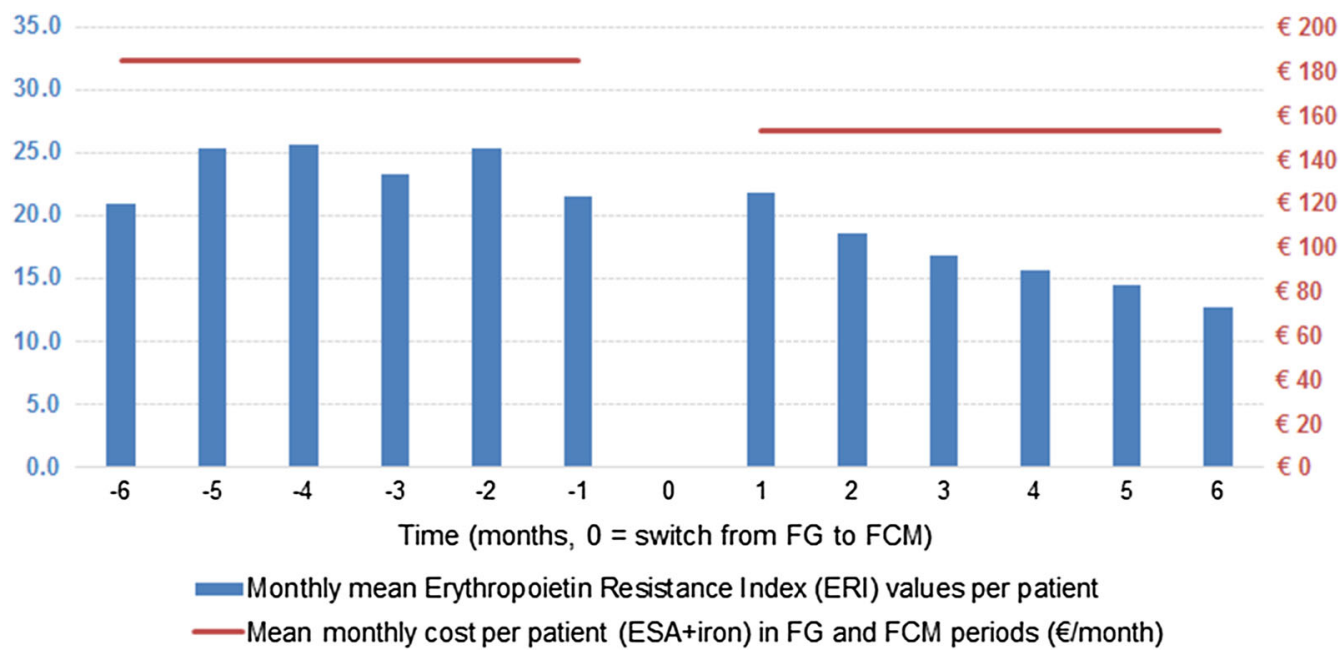

Fig. 3 Monthly Erythropoietin Resistance Index values and cost for drugs

use of ESA biosimilar, the cost per patients achieving $\mathrm{Hb}$ target values was estimated to be $€ 984$ vs. $€ 724$ (a saving of $26 \%$ ).

\section{DISCUSSION}

Anemia is a frequent and early complication of CKD [19]. It contributes to typical CKD symptoms (fatigue, reduced exercise tolerance, dyspnea, cognitive impairment, insomnia) and to disease progression and cardiovascular complications such as left ventricular hypertrophy and left ventricular diastolic dysfunction [20]. Although the etiology of renal anemia is multifactorial, its main cause is a lack of endogenous erythropoietin production, with a consequent reduction in bone marrow erythropoiesis. Treatment of anemia in CKD patients is expensive because of the high cost of erythropoietin. This results in higher direct healthcare costs in patients with CKD and anemia compared with those without anemia [21]. Good iron body stores are needed for the optimal 


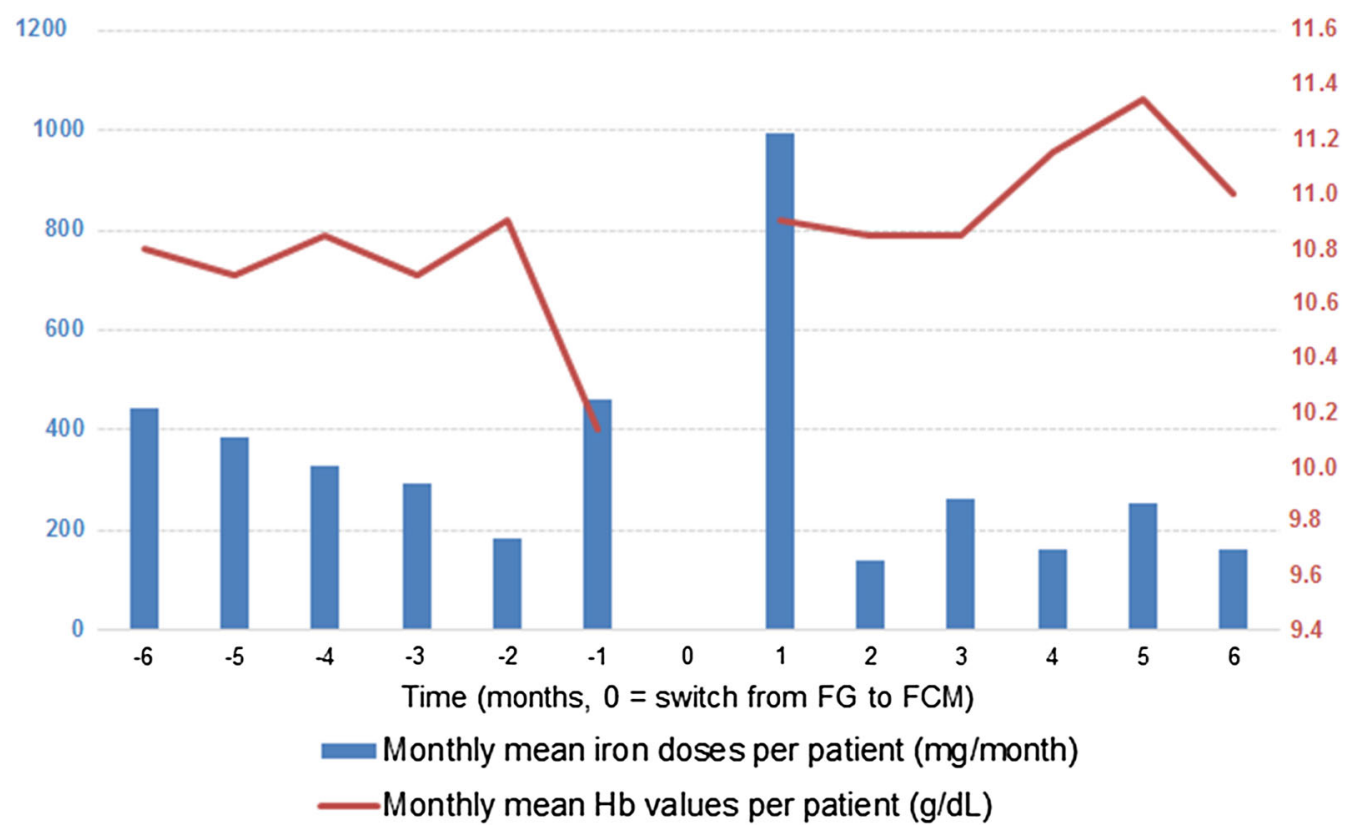

Fig. 4 IV iron administration schedule and mean $\mathrm{Hb}$ values over the two treatment periods

activity of erythropoietin and for curtailing doses. International guidelines recommend the use of the IV administration of iron in HD patients because of the quicker $\mathrm{Hb}$ improvement and lower ESA requirement compared with oral iron administration [4]. However, data concerning the use of different parenteral iron preparations are currently still limited in the context of dialysis [5]. Moreover, there is a lack of studies evaluating the economic consequences or cost-effectiveness of different iron IV formulations in this setting. To date, Wong et al. [22] published an economic evaluation aimed at estimating the healthcare costs and benefits of IV iron (iron sucrose and iron polymaltose) compared with oral iron in HD patients receiving ESAs. The study showed that the use of parenteral iron to achieve an $\mathrm{Hb}$ target between 9.5 and $12 \mathrm{~g} / \mathrm{dl}$ was cost-effective compared with oral iron therapy among HD patients with functional iron deficiency. Recently, an Italian study [23] reported that FCM was effective in correcting IDA and was associated with an important reduction in costs related to anemia management compared with ferric gluconate. However, that study was undertaken in non-dialysis CKD.
Findings from the present study show that switching from FG to FCM in adult HD patients with IDA allows a cost reduction per patient/month in the range $€ 14-46$, considering the two scenarios of use of biosimilar ESA or originator ESA, respectively. The analysis on the cost per patient at target showed savings in the range of $-36 \%$ and $-26 \%$ in the two scenarios considered. The cost component of the healthcare personnel had limited impact on the results.

In reference to clinical data, after the switch to FCM, Hb, ferritin and TSAT increased, while transferrin levels decreased, reflecting erythropoiesis that was less restricted by iron deficiency. A similar trend was already observed in a recent study by Hofman et al. [15] after the switch from IS to FCM. During the FG period, the values of ferritin were on average below the recommended threshold of $200 \mu \mathrm{g} / \mathrm{l}$, while after the switch mean values were in target in 4 out of 6 months. The ferritin levels reported in the first period are likely related to the average lower iron doses per single infusion because of the lower doses allowed with FG $(62.5 \mathrm{mg})$. In this context, FCM could reach much higher doses per single infusion (100 mg), thus inducing higher ferritin levels and a correct maintenance of ferritin and TSAT targets. Our real-life 
experience is in line with a recent publication by Diebold et al. [24], who demonstrated that after a single infusion of FCM, the ferritin levels increase rapidly and that the curve to baseline could cover 3-4 weeks at least.

The main clinical benefit from switching to FCM was the increase of Hb values, which paralleled an important dose reduction of ESA ( $-32 \%$ in the present study).

Furthermore, considering similar iron doses over the two periods, FCM was shown to be more effective than FG in restoring iron reserves, probably because of increased bioavailability of elemental iron in FCM compared with FG. Actually, both ferritin and the percentage of patients with TSAT $\geq 20 \%$ were always higher during FCM treatment in all the observed periods.

It is also important to highlight the progressive reduction of ERI when FCM was used, confirming lower requirements of ESA and consequently lower mean total cost for drugs (erythropoietin + iron) per patient (from $€ 185$ in the pre-switch period to $€ 153$ post-switch).

This study has a number of limitations that need to be addressed. It was conducted through a cost-minimization analysis, which basically does not consider differences in effectiveness of the compared treatments. We presented, in addition, a number of clinical parameters that could help highlight the advantages of the use of FCM over FG in HD patients with IDA. Regrettably, the retrospective nature of the study did not allow us to collect data on patients' quality of life in a prospective way in order to perform a cost-utility analysis, which would have provided a more comprehensive picture of the comparison between FG and FCM in a proper pharmacoeconomic context. For the same reason, we were not able to collect data on patients' out-of-pocket costs or productivity losses in order to consider the broader societal perspective in our analysis and give insights on the optimal resource allocation supporting an informed public discussion on the burden of the management of dialysis patients with IDA.

Other limitations, apart the small size of the investigated population, include the non-controlled and retrospective nature and being a single-center study. Actually, it was not a trial, but a real-world experience, where unpredictable situations may occur, such as the need to switch from FG to FCM. However, the monthly levels of different parameters assessed (pre- and post-switch) clearly depict the true trend of the investigated parameters. Another limitation relates to the difference in the monthly iron doses between the two periods; although the total 6-month dose was similar for FG and FCM (about $2000 \mathrm{mg}$ ), FG doses were progressively halved during the 5 months (from -6 to -2 ) and doubled in the following month $(-1)$. Anyway, no response was shown at month 0 , as $\mathrm{Hb}$ values continued to decrease until $9.9 \mathrm{~g} / \mathrm{dl}$. This excludes a possible effect of FG in the following month, which on the other hand could be explained by the FCM use.

Moreover, all patients with available followup ( 6 months of use of FG and 6 months of use of FCM) were considered in the study, so we were not able to analyze other possible patients as a control group that in the same 6-month period of FCM use remained on FG.

We assumed that all ESAs were bioequivalent, which means that there were no clinically relevant differences between ESA originators and ESA biosimilars. However, this could not be the case since the biosimilar of epoetin alpha has been reported to have 35\% lower activity than the corresponding originator in a realworld setting [25]. Thus, the reduced need for erythropoietin observed in the FCM period could actually underestimate the true savings in erythropoietin units in the scenario of use of ESA biosimilars; indeed, ESA biosimilar consumption should increase by $35 \%$ to maintain the same activity level as ESA originators leading to ESA biosimilar expenses of $€ 23,846$ and $€ 16,232$ for FG and FCM strategies, respectively (see Table 2, scenario with biosimilar ESA, for comparison). Consequently, the total savings considering this scenario with $+35 \%$ use of biosimilar ESAs would be $€ 5100$ (total cost for FG and FCM strategies of $€ 29,725$ and $€ 24,625$, respectively) instead of $€ 3126$.

A further limitation of our study was the influence by the type of dialysis (HD, hemodiafiltration) on ERI [26]. However, this study includes comparison of multiple data points within one patient for the entire period. Each 
patient serves as his/her own control, and the dialysis method was maintained during the 12-month observation period.

\section{CONCLUSION}

Based on the results of the current retrospective data, our analyses suggest that FCM compared with FG, considering the same cumulative dose over a 6-month period, improves the control of anemia and is cost-saving in dialysis patients with IDA. The notable improvement in iron parameters by FCM may also have a more general beneficial effect. Nephrologists are mainly focused on the management of anemia and are interested in iron deficiency because these are a compulsory requirement for anemia treatment. However, in several therapeutic areas, especially in congestive heart failure, there is now strong evidence that iron deficiency alone impacts the underlying disease, exercise capacity and quality of life, independently of anemia [9, 27-29]. This probably applies to HD patients whose congestive heart failure risk is high.

Future studies not limited to the analysis of costs but also considering patients' quality of life through the assessment of the cost-utility profile of FCM versus FG, possibly performed from the broader societal perspective, may provide further evidence on the sustainability of FCM for the treatment of adult HD patients with IDA.

\section{ACKNOWLEDGEMENTS}

Funding. The present study was funded by Vifor Pharma Italia Srl. The study sponsor also funded the journal's Rapid Service and Open Access fees. No interference occurred in carrying out the research project and in writing the manuscript, which was the sole responsibility of the authors.

Authorship. All named authors meet the International Committee of Medical Journal Editors (ICMJE) criteria for authorship for this article, take responsibility for the integrity of the work as a whole, and have given their approval for this version to be published.

Disclosures. Carla Rognoni has received fees for consultancies from the sponsor of the study. Vittorio Ortalda, Caterina Biasi and Giovanni Gambaro have nothing to disclose.

Compliance with Ethics Guidelines. The study was approved by the ethics committee of AOUI Verona (study 2047CESC, reference no. ITSP2018) and conformed to the Helsinki Declaration of 1964, as revised in 2013, concerning human and animal rights.

Open Access. This article is distributed under the terms of the Creative Commons Attribution-NonCommercial 4.0 International License (http://creativecommons.org/licenses/ by-nc/4.0/), which permits any noncommercial use, distribution, and reproduction in any medium, provided you give appropriate credit to the original author(s) and the source, provide a link to the Creative Commons license, and indicate if changes were made.

\section{REFERENCES}

1. Stauffer ME, Fan T. Prevalence of anemia in chronic kidney disease in the United States. PLoS One. 2014;9:e84943.

2. Wish JB, Aronoff GR, Bacon BR, et al. Positive iron balance in chronic kidney disease: how much is too much and howto tell? Am J Nephrol. 2018;47:72-83.

3. Macdougall IC. Iron supplementation in the nondialysis chronic kidney disease (ND-CKD) patient: oral or intravenous? Curr Med Res Opin. 2010;26:473-82.

4. Kidney Disease: Improving Global Outcomes (KDIGO) Anemia Work Group. KDIGO clinical practice guideline for anemia in chronic kidney disease. Kidney Int Suppl. 2012;2:279-335.

5. Bailie GR, Larkina M, Goodkin DA, et al. Variation in intravenous iron use internationally and over time: the Dialysis Outcomes and Practice Patterns Study (DOPPS). Nephrol Dial Transplant. 2013;28:2570-9. 
6. Coyne DW. The health-related quality of life was not improved by targeting higher hemoglobin in the Normal Hematocrit Trial. Kidney Int. 2012;82:235-41.

7. Pfeffer MA, Burdmann EA, Chen C-Y, et al. A trial of darbepoetin alfa in type 2diabetes and chronic kidney disease. N Engl J Med. 2009;361:2019-32.

8. Rampton D, Folkersen J, Fishbane S, Hedenus M, Howaldt S, Locatelli F, et al. Hypersensitivity reactions to intravenous iron: guidance for risk minimization and management. Haematologica. 2014;99(11):1671-6.

9. Auerbach M, Deloughery T. Single-dose intravenous iron for iron deficiency: a new paradigm. Hematology Am Soc Hematol Educ Program. 2016;2016(1):57-66.

10. Macdougall IC, Bock AH, Carrera F, Eckardt K-U, Gaillard C, Van Wyck D, et al. FIND-CKD: a randomized trial of intravenous ferric carboxymaltoseversus oral iron in patients with chronic kidney disease and iron deficiency anaemia. Nephrol Dial Transplant. 2014;29:2075-84.

11. Van Wyck DB, Roppolo M, Martinez CO, Mazey $\mathrm{RM}$, McMurray S. A randomized, controlled trial comparing IV iron sucrose to oral iron in anemic patients with nondialysis-dependent CKD. Kidney Int. 2005;68:2846-56.

12. Agarwal R, Rizkala AR, Bastani B, Kaskas MO, Leehey DJ, Besarab A. A randomized controlled trial of oral versus intravenous iron in chronic kidney disease. Am J Nephrol. 2006;26(5):445-54 (Epub 2006 Oct 11).

13. Covic A, Mircescu G. The safety and efficacy of intravenous ferric carboxymaltose in anaemic patients undergoing haemodialysis: a multi-centre, open-label, clinical study. Nephrol Dial Transplant. 2010;25:2722-30.

14. Charytan C, Bernardo MV, Koch TA, Butcher A, Morris D, Bregman DB. Intravenous ferric carboxymaltose versus standard medical care in the treatment of iron deficiency anemia in patients with chronic kidney disease: a randomized, active-controlled, multi-center study. Nephrol Dial Transplant. 2013;28(4):953-64.

15. Hofman JMG, Eisenga MF, Diepenbroek A, et al. Switching iron sucrose to ferric carboxymaltose associates to better control of iron status in hemodialysis patients. BMC Nephrology. 2018;19:242.

16. Macdougall IC, White C, Anker SD, et al. Randomized trial comparing proactive, high-dose versus reactive, low-dose intravenous iron supplementation in hemodialysis (PIVOTAL): study design and baseline data. Am J Nephrol. 2018;48(4):260-8.

17. Macdougall IC, White C, Anker SD, et al. Intravenous iron in patients undergoing maintenance hemodialysis. N Engl J Med. 2019;380(5):447-58.

18. Duenas A. Cost-minimization analysis. In: Gellman MD, Turner JR, editors. Encyclopedia of behavioral medicine. New York: Springer; 2013.

19. Grote Beverborg N, van Veldhuisen DJ, van der Meer P. Anemia in heart failure: still relevant? JACC Heart Fail. 2018;6(3):201-8.

20. Chang JM, Chen SC, Huang JC, Su HM, Chen HC. Anemia and left ventricular hypertrophy with renal function decline and cardiovascular events in chronic kidney disease. Am J Med Sci. 2014;347(3):183-9.

21. Smith RE. The clinical and economic burden of anemia. Am J Manag Care. 2010;16(Suppl):S59-66.

22. Wong G, Howard K, Hodson E, Irving M, Craig JC. An economic evaluation of intravenous versus oral iron supplementation in people on haemodialysis. Nephrol Dial Transplant. 2013;28(2):413-20.

23. Minutolo R, Liberti ME, Berto P. Economics of intravenous ferric carboxymaltose for treatment of iron deficient anaemia in patients with non-dialysis chronic kidney disease: a pilot study in Italy. Nephrol Dial Transplant. 2018;33(Suppl 1):i457.

24. Diebold M, Kistler AD. Evaluation of iron stores in hemodialysis patients on maintenance ferric carboxymaltose dosing. BMC Nephrol. 2019;20(1):76.

25. Minutolo R, Borzumati M, Sposini S, Abaterusso C, Carraro G, Santoboni A, et al. Dosing penalty of erythropoiesis-stimulating agents after switching from originator to biosimilar preparations in stable hemodialysis patients. Am J Kidney Dis. 2016;68(1):170-2.

26. Panichi V, Scatena A, Rosati A, Giusti R, Ferro G, Malagnino E, et al. High-volume online haemodiafiltration improves erythropoiesis-stimulating agent (ESA) resistance in comparison with low-flux bicarbonate dialysis: results of the REDERT study. Nephrol Dial Transplant. 2015;30(4):682-9.

27. Anker SD, Comin Colet J, Filippatos G, Willenheimer R, Dickstein K, Drexler H, et al. Ferric carboxymaltose in patients with heart failure and iron deficiency. N Engl J Med. 2009;361(25):2436-48.

28. Ponikowski P, Filippatos G, Colet JC, Willenheimer $\mathrm{R}$, Dickstein $\mathrm{K}$, Lüscher $\mathrm{T}$, et al. The impact of intravenous ferric carboxymaltose on renal 
function: an analysis of the FAIR-HF study. Eur J Heart Fail. 2015;17(3):329-39.

29. Ponikowski P, van Veldhuisen DJ, Comin-Colet J, Ertl G, Komajda M, Mareev V, et al. Beneficial effects of long-term intravenous iron therapy with ferric carboxymaltose in patients with symptomatic heart failure and iron deficiency. Eur Heart J. 2015;36(11):657-68. 